\title{
STUDI LITERATUR TEKNIK PEMERIKSAAN RADIOLOGI VESIKA URINARIA PADA PASIEN ANAK DENGAN KLINIS VESICOURETERAL RELFLUX (VUR)
}

\author{
Sri Hartati ${ }^{1}$, Naomi Heriputranti ${ }^{2}$ \\ ${ }^{1,2}$ Akademi Teknik Radiodiagnostik dan Radioterapai Nusantara Jakarta
}

Corresponding author: Sri Hartati

Email: hartati2311@yahoo.com

\begin{abstract}
Background: VUR (Vesicoureteral Reflux) is a condition in which urine flows back from the bladder to one or both ureters or sometimes to the kidneys. Several types of modalities are used to support this clinical examination. The modalities that can be used to support this examination include: Voiding Cystourethrography, DRCG (Direct Radionuclide Cystourethrography), ceVUS (Contrast Enhancement Voiding Urosonography), and MRI (Magnetic Resonance Imaging)

Methods: This research is a type of research that is library research, a method of collecting library data or research where the object of research is explored through a variety of library information (books, proceedings, articles and scientific journals).

Results: Radiological examination of the clinical bladder with VUR can be performed with various radiological modalities including Voiding Cystourethrography, Direct Radionuclide Cystography (DRCG), Magnetic Resonance Imaging (MRI), and Contrast Enhancement Urosonography (ceVUS). Each examination uses a contrast material that is adjusted to the modality used.

Conclusions: From the various modalities that can be used, it is assessed from the level of effectiveness and efficiency as well as the minimum radiation exposure dose. The ceVUS technique is the most appropriate technique to describe VUR because it does not use ionizing radiation but this technique will be difficult to perform in certain conditions such as the pathological condition of the patient.
\end{abstract}

Keyword :Urography, Vesika Urinaria, Vesicouretal Reflux

\section{Pendahuluan}

VUR adalah diagnosis urologis yang umum pada anak-anak, dengan perkiraan prevelensi $0,4-$ $1,8 \%$ pada populasi umum anak, dan lebih dari $30 \%$ pada mereka yang memilki riwayat ISK. Dilatasi saluran kemih bagian atas pada pencitraan prenatal juga menunjukkan VUR, dengan banyak penelitian melaporkan bahwa refluks hadir pada $10-20 \%$ anak-anak dengan hidronefrosis yang terdeteksi secara antenatal.

Infeksi saluran kemih (ISK), salah satu infeksi bakteri yang paling umum terjadi pada masa bayi dan anak usia dini, sering dikaitkan dengan vesicoureteral reflux (VUR). Vesicouretal reflux didefinisikan sebagai aliran retrograde abnormal urin dari kandung kemih ke ureter melintasi vesicoureteric junction (VUJ). VUR adalah penyebab fungsional tersering kedua dari obstruksi di saluran kemih (setelah obstruksi sambungan pelviureteric) dan sering terjadi terjadi pada bayi dan anak usia dini. VUR yang tidak diobati menjadi predisposisi infeksi saluran kemih yang dapat berkembang menjadi spectrum nefropati refluks.

Oleh karena itu, diagnosis dini VUR sangat ditekankan. Berbagai modalitas pencitraan telah digunakan untuk mendeteksi VUR, diantaranya adalah Voiding Cystourethrography (VCUG), Radionuclide Cystography (Direct and Indirect), Contrast-Enhance Voiding Urosonography (ceVUS), serta Magnetic Resonance Imaging.

\section{Metode}

Jenis penelitian ini adalah penelitian kepustakaan (library research) yaitu serangkaian penelitian yang berkenaan dengan metode pengumpulan data pustaka atau penelitian yang digali melalui beragam informasi kepustakaan 
(buku, prosiding, artikel, dan jurnal ilmiah). Penelitian kepustakaan atau kajian literatur (literature review) merupakan penelitian yang mengkaji atau meninjau secara kritis pengetahuan, gagasan, atau temuan yang terdapat di dalam tubuh literatur berorientasi akademik (academic-oriented literature), serta merumuskan kontribusi teoritis dan metodologisnya untuk topik tertentu. Fokus penelitian kepustakaan yang penulis lakukan adalah terkait dengan Teknik Pemeriksaan Radiologi Kandung Kemih Klinis VUR

\section{Hasil dan Pembahasan}

Berdasarkan hasil analisa jurnal terkait pemeriksaan vesika urania pada pasien anak dengan klinis VUR, didapatkan hasil sebagai berikut :

\section{1) Pemeriksaan Ultrasonografi}

Pada jurnalnya Carmina Duran et al (2017) dengan judul "Contrast-Enhanced Voiding Urosonography for Vesicoureteral Reflux Diagnosis in Children" mengungkapkan bahwa Contrast-Enhancement Voiding Urosonography adalah teknik pencitraan radiologi untuk mempelajari struktur saluran kemih setelah pemberian bahan kontras intravesika. Awalnya, pemeriksaan ini diindikasikan terutama untuk mempelajari refluks vesicoureteral (VUR). Namun, karena kemampuan ceVUS untuk menggambarkan struktur uretra, ceVUS sekarang diindikasikan untuk pemeriksaan seluruh saluran kemih. Selain dapat membantu memastikan diagnosis VUR, teknik ceVUS juga dapat digunakan untuk menggambarkan kondisi patologis uretra obstruktif dan non-obstruktif. Dengan demikian, ceVUS telah menjadi pengganti utama Voiding Cystourethrography untuk studi saluran kemih pada pasien anak-anak, karena ceVUS menyediakan gambar berkualitas tinggi dan dapat membantu mendiagnosis gangguan saluran kemih tanpa menggunakan radiasi pengion. Selain itu, dalam temuan dari berbagai penelitian, para peneliti telah menunjukkan keamanan ceVUS, dengan tidak ada efek samping parah yang dilaporkan dengan menggunakan metode ini.

Metode ceVUS dapat digunakan pada pasien yang sama dan dalam kondisi patologis yang sama sepert VCUG. Namun demikian, teknik ceVUS bisa lebih sulit pada kondisi tertentu seperti kondisi patologis, misalnya pada scoliosis parah yang menyulitkan untuk menemukan dan menggambarkan ginjal ; pada ectopia ginjal yang menyilang dimana gas di loop usus yang berdekatan dapat menghalangi penggambaran. Ketidakmampuan untuk mendapatkan gambar tunggal yang menunjukkan seluruh saluran kemih dapat membuat interpretasi pemeriksaan ceVUS menjadi sulit.

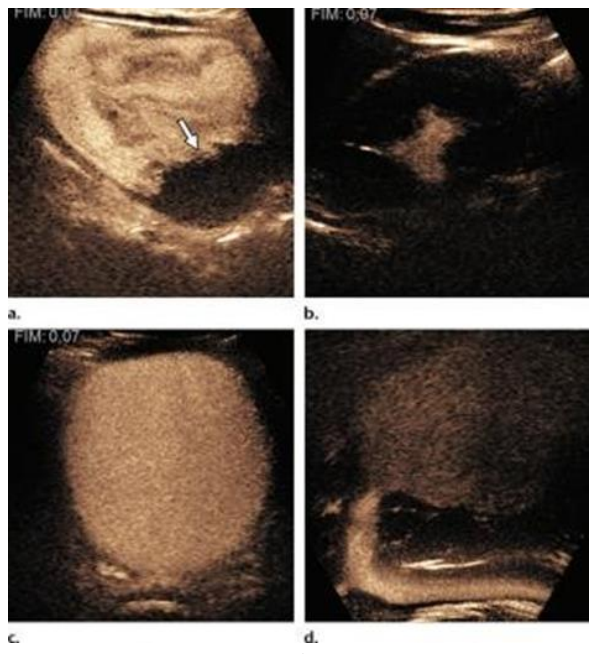

Gambar 1

(a) kadar urin pada bayi laki-laki usia 7 bulan dengan infeksi saluran kemih, (b) VUR grade 2 di ginjal kiri, (c) gambar ceVUS menunjukkan pengisian kandung kemih yang homogen tanpa level apapun, (d) citra ceVUS dengan probe ditempatkan pada sumbu longitudinal.

\section{2) Pemeriksaan Kedokteran Nuklir}

Pada Jurnalnya Dr. MD Khizer Razak and Dr. Sudhakar R (2019) yang berjudul "A prospective study comparing direct radionuclide cystography (DRCG) with voiding cystourethrography in the detection and grading of vesicoureteric reflux in children" mengungkapkan VUR adalah masalah umum pada kelompok usia anak. Tes skrining awal biasanya berupa USG yang sangat bergantung pada tanda-tanda tidak langsung dari VUR seperti hidronefrosis, hidroureteronefrosis, atau hidroureter yang lebih rendah untuk menyarankan diagnosis. Akhir-akhir ini, DRCG diadopsi sebagai alat investigasi alternative atau pelengkap untuk diagnosis VUR.

Namun demikian, beberapa studi telah membandingkan kedua tes dalam mendeteksi VUR. Dalam sebuah peneitian terhadap 105 unit refluks, McLaren et al menunjukkan DRCG menjadi lebih sensitive (91\% vs $45 \%)$ dalam mendeteksi VUR pada bayi yang leih muda, 
terlepas dari kelasnya. Beberapa VUR yang terlewat di DRCG sebagian besar adalah kelas rendah. Oleh karena itu, nilai VUR yang lebih tinggi lebih baik di deteksi di DRCG dibandingkan dengan VCUG. Sensitivitas DRCG yang lebih baik sering dianggap berasal dari pengamatan real-time terus menerus selama periode yang relative lebih lama daripada VCUG.

Dalam catatan bahwa DRCG terkadang gagal mendeteksi refluks nilai yang lebih rendah daripada nilai yang lebih tinggi. Telah dikemukakan bahwa sifat intermiten dari refluks derajat rendah dan radioaktivitas kandung kemih yang tupang tindih dapat berkontribusi pada hilangnya sensitivitas ini. Namun factor serupa dari cairan yang tidak dibedah dan variasi VUR pada VCUG berturut-turut juga dapat mengakibatkan nilai yang lebih rendah terlewatkan pada VCUG.

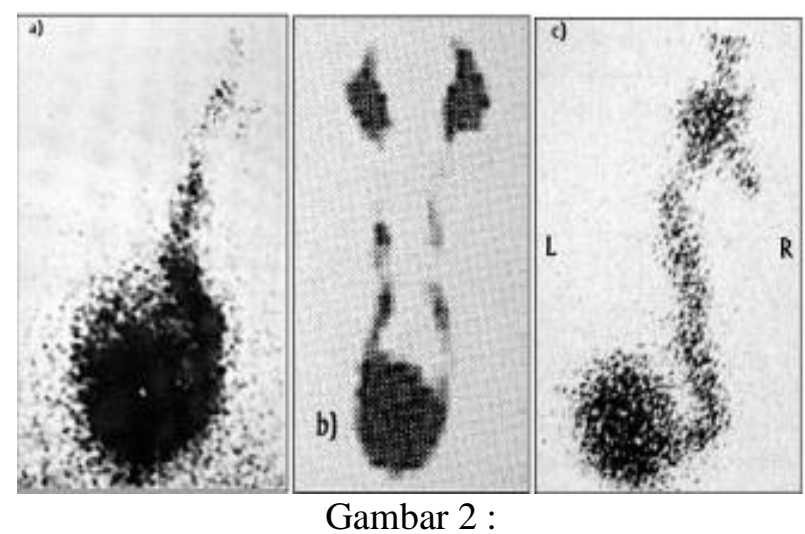

(a) DRCG dengan VUR kanan grade 4, (b) DRCG dengan VUR kanan garde 3 dan (c) DRCG dengan VUR kanan Grade 5

\section{3) Pemeriksaan MRI}

Menurut Norihiro Murakami et al (2018) pada artkel nya yang berjudul "Ureteral dilatation detected in magnetic resonance imaging predicts vesicoureteral reflux in children with urinary tract", Evaluasi penggunaan MRI pada anak-anak dengan ISK. Studi pertama yang mengungkapkan hubungan antara dilatasi ureter di MRI dan VUR. Menunjukkan bahwa temuan dilatasi ureter yang terdeteksi pada MRI pada fase akut ISK sangat terkait dengan adanya VUR; oleh karena itu, MRI dapat digunakan sebagai tes skrining untuk VUR. Pada pasien ISK, ultrasonography telah digunakan secara umum sebagai tes skrining untuk VUR, tetapi itu mencapai sensitivitas hanya sekitar $40 \%$ dalam penelitian dan 5-28\% dalam peneitian sebelumnya. Data menunjukkan bahwa evaluasi ureteral dilatasi menggunakan MRI dapat diterapkan untuk memprediksi VUR, terutama VUR bermutu tinggi yang kadang-kadang diperlukan perawatan bedah.
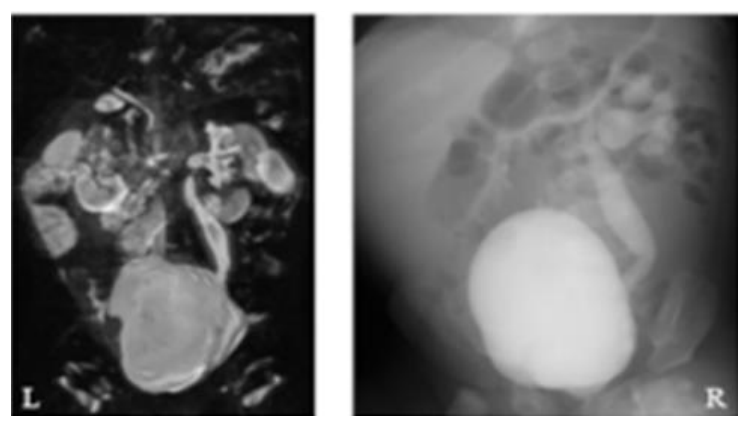

Gambar 3

Diagnosis ISK bagian atas Gambaran MRI DWI pada anak umur 6 bln dengan klinis VUR grade 4

Beberapa laporan menunjukkan bahwa DWMRI mencapai sensitivitas dan spesifitas yang sangat baik (keduanya lebih dari 90\%) untuk diagnosis ISK bagian atas. Bahwa pasien ISK bagian atas dengan lesi ginjal tipe A pada DWMRI memiliki kadar CRP dan skor MRI yang lebih tinggi. Hal ini mungkin menunjukkan bahwa lesi tipe A berkorelasi dengan AFBN, yang merupakan bentuk dari ISK bagian atas.

\section{4) Pemeriksaan Cystouretrogarfi}

Menurut Angela M Arlen et al (2019) dalam artikelnya yang berjudul "New trends in voiding cystourethrography and vesicoureteral reflux: Who, when and how?", voiding Cystourethrogram menggambarkan uretra dan kandung kemih selama pengisian dan pengosongan kandung kemih, serta ureter dan ginjal ketika terjadi refluks, dan dianggap sebagai standar emas untuk mendiagnosis vesicouretral reflux. Setelah terdeteksi, pilihan terapeutik untuk refluks urin beragam, mulai dari observasi dengan atau tanpa profilaksis antibiotic dosis rendah hingga berbagai intervensi operasi.

Menurut jurnal ini, masih ada kontroversi mengenai indikasi VCUG dan manajemen optimal dari refluks vesikoureteral primer pada populasi anak. Namun, standarisasi terbaru dari protocol VCUG telah menciptakan consensus tentang cara terbaik untuk melakukan tes ini. Baik volume pada permulaan VUR mudah diakses dari VCUG standard dan telah terbukti meningkatkan 
kemampuan untuk memprediksi resolusi VUR dan terobosan ISK.

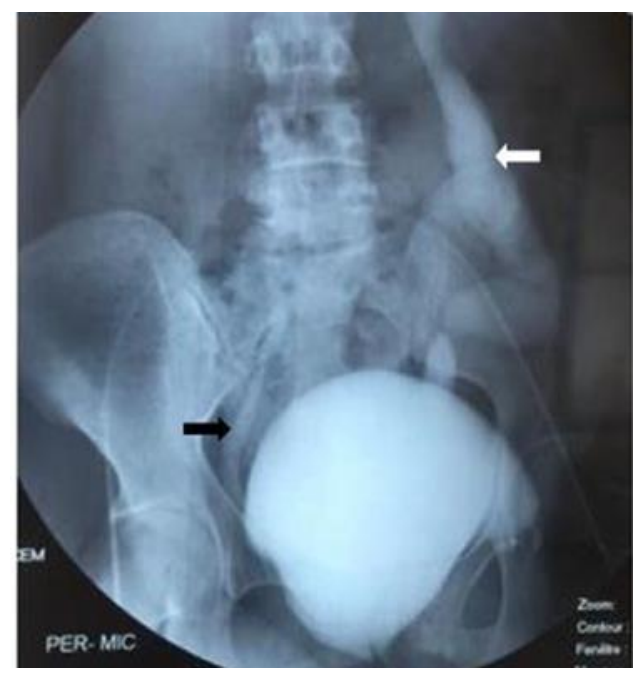

Gambar 4 :

Refluks vesikoureteral grade IV bilateral di sebelah kiri (panah putih) dan refluks vesikoureteral tingkat I di sebelah kanan (hitam)

Voiding Cystourethrography adalah metode konvensional dan paling diterima dan umumnya dianggap sebagai standar referensi untuk diagnosis karena memberikan gambaran anatomi yang baik yang sangat penting dalam pencitraan yang berhubungan dengan anomali struktural (misalnya katup uretra posterior) dan memberikan penilaian yang akurat. Radionuclide Cystourethrography (Direct and Indirect) merupakan tes yang relative lebih baru yang memiliki paparan radiasi dan berguna baik antenatal maupun postnatal untuk menyaring tanda-tanda tidak langsung VUR.

Contrast-Enhanced Voiding Urosonography (ceVUS) adalah teknik pencitraan dinamis yang memungkinkan untuk mempelajari struktur saluran kemih setelah pemberian bahan kontras intravesika. Manfaat utama ceVUS adalah tidak menggunakan radiasi pengion.

VCUG (Voiding Cystourethrography) memiliki kelebihan yaitu dianggap sebagai standard referensi, paling mudah diterima, mampu memberikan gambaran anatomi yang baik yang sangat penting dalam pencitraan yang berhubungan dengan anatomi structural (misalnya katup uretra posterior) dan memberikan penilaian yang akurat. Namun, memiliki kelemahan utamanya adalah katerisasi kandung kemih dan paparan radiasi yang terlalu besar. ${ }^{(4)}$

CeVUS (Contrast-Enhancement Voiding Urosonography) memiliki kelebihan dalam mendeteksi Vesicoureteral Reflux yaitu memungkinkan evaluasi morfologi dan fungsional dari seluruh saluran kemih, kontras yang digunakan tidak memiliki efek samping terhadap hati dan ginjal, dan tidak menggunakan radiasi pengion. Di samping kelebihan dari teknik ini, ceVUS juga memiliki kelemahan pada kondisi patologis tertentu contoh pada kasus patologis scoliosis yang menyulitkan untuk menemukan dan menggambarkan ginjal. ${ }^{(5)}$

MRI (Magnetic Resonance Imaging) memiliki kelebihan yaitu dapat memberikan gambaran dengan berbagai macam potongan serta pada MRI tidak menggunakan ionisasi radiasi tetapi MRI juga memiliki kelemahan yaitu dari segi kenyamanan pasien karena ada beberapa kasus dimana pasien merasa tidak nyaman saat berada di dalam mesin MRI atau pasien yang memiliki claustrophobia. ${ }^{(3)}$

Sedangkan DRCG (Direct Radionuclide Cystography) memiliki kelebihan yaitu bisa mendiagnosis VUR pada penerima trans ginjal, bisa mendiagnosis VUR pada penyakit disfungsi kandung kemih seperti kandung kemih neurogenik dimana evaluasi serial diperlukan. Tetapi DRCG (Direct Radionuclide Cystography) memiliki kontra indikasi utama yaitu infeksi saluran kemih aktif. Jadi, setiap pasien yang akan menjalani DRC harus memiliki kultur urin negative.

Keempat modalitas yang digunakan masingmasing memiliki perbedaan dan persamaan dalam mendeteksi VUR. Persamaan dari keempat modalitas tersebut adalah efektif dalam mendeteksi atau membaca adanya VUR serta beberapa modalitas seperti Voiding Cystourethrography, Direct Radionuclide Cystography (DRCG), dan Contrast Enhancement Urosonography menggunakan bahan kontras sebagai pendukung dalam memvisualisasikan VUR, hanya saja bahan kontras yang digunakan berbeda.

Pada teknik ceVUS dan DRCG jika dilakukan pada pasien yang memiliki kondisi tertentu, kondisi pasca operasi atau kondisi bawaan yang nantinya dapat mempengaruhi dari hasil gambaran. Contoh pada pasien scoliosis sehingga gambaran ginjal akan terhalang dan sulit mendapatkan gambaran secara keseluruhan dari saluran kemih. Teknik ceVUS juga dinilai lebih efektif dan efisien dibanding teknik lainnya dikarenakan tidak menggunakan radiasi pengion sehingga paparan radiasi hampir tidak ada. Dari segi hasil gambaran, teknik Voiding Cystourethrography dan DRCG dianggap sebagai standar referensi untuk diagnosis. Karena gambaran yang dihasilkan meliputi 
anatomi structural serta mampu menampilkan tingkatan grade pada VUR.

Table 1. Tabel Pemeriksaan Vesika Urinaria dengan berbagai modalitas Radiologi

\begin{tabular}{cl}
\hline No & \multicolumn{3}{c}{ MODALITAS RADIOLOGI } \\
\hline 1. & Voiding Cystourethrography metode \\
konvensional, paling umum dan \\
standar referensi untuk diagnosis \\
karena memberikan gambaran anatomi \\
yang baik yang sangat penting dalam \\
pencitraan yang berhubungan dengan \\
anomali struktural dan memberikan \\
penilaian yang akurat. \\
\hline 2. & Pemriksaan ceVUS memungkinkan \\
& untuk mempelajari struktur saluran \\
kemih dengan pemberian bahan \\
kontras intravesika. Pemeriksaan ini \\
tidak menggunakan radiasi pengion.
\end{tabular}

3. Direct Radionuclide Cystography,bisa mendiagnosis VUR pada penerima trans ginjal, bisa mendiagnosis VUR pada penyakit disfungsi kandung kemih seperti kandung kemih neurogenik dimana evaluasi serial diperlukan. Setiap pasien yang akan menjalani DRCG harus memiliki kultur urin negative.

4. MRI (Magnetic Resonance Imaging) dapat memberikan gambaran dengan berbagai macam potongan serta tidak menggunakan ionisasi radiasi tetapi merupakan kontra indikasi untuk pasien dengan implant logam dan claustrophobia.

\section{Kesimpulan}

Teknik Pemeriksaan Kandung Kemih klinis VUR dapat dilakukan dengan berbagai modalitas seperti, Voiding Cystography, DRCG (Direct Radionuclide Cystography), ceVUS (Contrast-Enhancement Voiding Urosonography). Untuk persiapan alat dan bahan tergantung dari modalitas yang digunakan, umumnya pasien diminta untuk puasa serta mengosongkan kandung kemih agar tidak terjadi adanya gambaran lain. Teknik ceVUS yang dinilai paling tepat untuk mendiagnosis VUR dengan alasan tidak menggunakan radiasi pengion sehingga tidak ada paparan radiasi yang mengenai pasien tapi teknik ini akan menjadi sulit jika menghadapi suatu kondsi tertentu seperti kondisi patologis dari pasien itu sendiri.

\section{Daftar Pustaka}

Likartsis C, Printza N, Notopoulos A. Radionuclide techniques for the detection of vesicoureteral reflux and their clinical significance [Internet]. Vol. 23, Hell J Nucl Med. 2020. Available from: www.nuclmed.gr

Arlen AM, Cooper CS. New trends in voiding cystourethrography and vesicoureteral reflux: Who, when and how? Vol. 26, International Journal of Urology. Blackwell Publishing; 2019. p. 440-5.

Murakami N, Kawada J ichi, Watanabe A, Arakawa T, Kano T, Suzuki T, et al. Ureteral dilatation detected in magnetic resonance imaging predicts vesicoureteral reflux in children with urinary tract infection. PLoS One. 2018 Dec 1;13(12).

Razak K, Sudhakar D. A prospective study comparing direct radionuclide cystography with voiding cystourethrography in the detection and grading of vesicoureteric reflux in children [Internet]. Vol. 1, 30 International Journal of Multidisciplinary Trends. 2019. Available from: www.multisubjectjournal.com

Duran C, Beltrán VP, González A, Gómez C, del Riego J. Contrast-enhanced voiding urosonography for vesicoureteral reflux diagnosis in children. Radiographics. 2017 Oct 1;37(6):1854-69.

Evelyn C. Pearce. Anatomi dan Fisiologi untuk Paramedis. In PT Gramedia Pustaka Utama, Jakarta; 2016. p. 298-305.

Mattoo TK, Chesney RW, Greenfield SP, Hoberman A, Keren R, Mathews R, et al. Renal scarring in the randomized intervention for children with vesicoureteral reflux (RIVUR) trial. Clin J Am Soc Nephrol. 2016;11(1):54-61.

Snodgrass WT, Bush NC. Vesicoureteral reflux. Pediatr Urol Evid Optim Patient Manag. 2013;19-33.

Weik MH, Weik MH. Radiogram. Computer Science and Communications Dictionary. 2000. 1403-1403 p.

Sauer A, Wirth C, Platzer I, Neubauer H, Veldhoen S, Dierks A, et al. Off-label-use of sulfurhexafluoride in voiding urosonography for 
diagnosis of vesicoureteral reflux in children: A survey on adverse events. World J Clin Pediatr. 2017;6(1):52.

Silay MS, Spinoit AF, Bogaert G, Hoebeke P, Nijman R, Haid B. Imaging for Vesicoureteral Reflux and Ureteropelvic Junction Obstruction. Eur Urol Focus. 2016;2(2):130-8.

Arthurs OJ, Edwards AD, Joubert I, Graves MJ, Set PAK, Lomas DJ. Interactive magnetic resonance imaging for paediatric vesicoureteric reflux (VUR). Eur J Radiol [Internet]. 2013;82(3):e112-9. Available from:

http://dx.doi.org/10.1016/j.ejrad.2012.10.02 